\title{
Large B-Cell Lymphoma with T-Cell-Rich Background and Nodules Lacking Follicular Dendritic Cell Meshworks: A Case Report with Complete Response to Chemotherapy and a Review of the Literature
}

\author{
Walid Shalata *a, Ismaell Massalha a , Kayed Al-Athamen ${ }^{\text {b }}$ \\ ${ }^{a}$ The Legacy Heritage Oncology Center \& Dr. Larry Norton Institute, Soroka Medical Center \& Ben-Gurion University, \\ Beer-Sheva, Israel. \\ ${ }^{\mathrm{b}}$ Department of Hematology, Soroka University Medical Center, Faculty of Health Sciences, Ben Gurion University, \\ Beer Sheva, Israel.
}

*Corresponding Author: Dr. Walid Shalata, MD, Resident Physician in Oncology, The Legacy Heritage Oncology Center \& Dr. Larry Norton Institute, Soroka Medical Center \& Ben-Gurion University, Beer-Sheva, Israel; walid.shalata@gmail.com

Received: 24 October 2020;

Accepted: 18 November 2020;

Published: 24 November 2020

\begin{abstract}
In this report, we describe a 38-year-old male with a very rare type of lymphoma, large B cell lymphoma with $\mathrm{T}$ cell-rich background and nodules lacking follicular dendritic cell meshworks (THRLBCL). In 2016 the patient presented hot flashes and night sweats (B-symptoms) and peripheral edema. He was treated with R-CHOP (doxorubicin, vincristine, cyclophosphamide, rituximab and Prednisone) chemotherapy, a Positron emission tomography-computed tomography (PET-CT) scan was performed after four cycles of treatment which showed radiologic complete response and blood test (complete blood count (CBC)) results showed normal ranges. As of September, 2020 he patient remains in complete remission.

We searched the literature for descriptions of cases spanning the diagnostic spectrum of THRLBCL and we identified only five cases worldwide. The last reported case was in 2014 with distinctive features that were difficult to classify according to the World Health Organization criteria or previously described variants.

Our patient is the sixth case of THRLBCL to be reported. He is the youngest of the reported cases and the first from Israel and the Middle East.
\end{abstract}

Keywords: Large B-cell lymphoma, T-cell lymphoma, chemotherapy, R-CHOP Protocol

\section{Introduction}

$\mathrm{T}$ cell histiocyte rich large $\mathrm{B}$ cell lymphoma (THRLBCL) is a sporadic sub-variant of lymphoma accounting for $1-2 \%$ of diffuse large B cell lymphomas (DLBCL). It is histologically characterized by a few scattered large malignant $B$ cells, which are typically $<10 \%$ of the cell population, in a background of reactive $\mathrm{T}$ cells and histiocytes ${ }^{[1]}$, and needs to be distinguished from nodular lymphocyte-predominant Hodgkin lymphoma (NLPHL), which is characterized by nodular and diffuse growth of scattered large neoplastic B cells associated with follicular dendritic cell (FDC) meshworks ${ }^{[2]}$. Atypical patterns, which are associated with different clinical outcomes were previously reported by Hartmann and his colleagues ${ }^{[3]}$, including one extreme rare variant expressing a T-cell-rich background with lacking FDC meshworks that could overlap with T-cell/histiocyte-rich large B-cell lymphoma ${ }^{[2,4]}$. We discuss the diagnostic challenge in this clinical scenario, as well as management considerations referring to the five other cases reported to date ${ }^{[5]}$. All cases completely lacked FDC meshworks despite a prominent nodular growth pattern. Large atypical cells in all cases were CD20+ CD30- CD15- B cells ${ }^{[5]}$.

In this study, we present the clinical, histological diagnostic, and therapeutic features of the sixth known case of large B-cell lymphoma with a nodular or partially nodular growth pattern and abundant $\mathrm{T}$ cells in the background but lacking FDC meshworks within the nodules. We think this case should raise awareness about an under recognized variant with clinical and pathological overlap between NLPHL and THRLBCL, which require further guidelines for their diagnosis and management

\section{Case report}

A 35-year old male with a history of asthma, was referred to the emergency department in October 2016 by a primary care 
physician due to chronic leukocytosis average of 14 (normal range $4.8-10.8 * 10^{\wedge} 3 / \mathrm{ul}$ ) and thrombocytosis average of 450 (normal range $130-140 * 10^{\wedge} 3 / \mathrm{ul}$ ), hot flashes, night sweats and peripheral edema over the past two months. There was no family history of cancer.

Physical examination revealed peripheral edema. Remainder of physical examination including cardiac auscultation was normal. Electrocardiogram showed normal sinus rhythm .Routine laboratory investigations (complete blood count, and biochemical profile) showed: anemia, monocytosis, leukocytosis neutrophilia and thrombocytosis (Table 1.). He was admitted to the hospital for further evaluation (Tables 2 and 3.). The patient underwent total body CT-scan (computed tomographic) which showed significant lymph node enlargement with retroperitoneal lymphadenopathy (Figure.1 A red square), (The largest retroperitoneal node was $1.8 \mathrm{~cm}$ in diameter) more on left side and several enlarged nodes in the left iliac area, the largest $4 \mathrm{~cm}$ in diameter (Figure.1 A and B yellow square) around and edema. A lymph proliferative disorder was suspected. Deep venous thrombosis was excluded by ultrasound (US) of the lower extremities. TSH was in normal range, excluding pretibial myxedema.
For further investigation the patient underwent a positron emission tomography-computed tomography (PET-CT) (Figure.2 A) which showed hyper-metabolic uptake and lymphadenopathy of the retroperitoneal and left iliac areas.

A lymph node biopsy was taken (from the left iliac area) under US guidance. Histopathologic findings were suspicious for a large B cell lymphoma. JAK2 mutation and BCR-ABL mutation were negative. The case was sent for consultation to the Department of Pathology, Stanford University, USA. The histopathologic findings at consultation were: Large B-cell lymphoma with $\mathrm{T}$-cell rich background and nodules lacking follicular dendritic cell meshworks (Table 4.)

A multidisciplinary conference came to the conclusion that the patient should be treated with six cycles of chemotherapy (R$\mathrm{CHOP}$ protocol). He received systemic intravenous therapy consisting of doxorubicin $50 \mathrm{mg} / \mathrm{m} 2$, vincristine $1.4 \mathrm{mg} / \mathrm{m} 2$, cyclophosphamide $750 \mathrm{mg} / \mathrm{m} 2$, rituximab $375 \mathrm{mg} / \mathrm{m} 2$ all given on day 1 every 21 days. After four cycles the patient underwent PETCT (Figure.1 C), (Figure.2 B) which showed no evidence of disease (NED) and CBC tests were in the normal ranges. After the sixth cycle the PET-CT also showed NED. Most recent PET-CT done in July 2020 which also showed NED (Figure.1 D), (Figure.2 C).

Table 1: Patient's Complete Blood Count (CBC), Coagulation and Chemistry.

\begin{tabular}{|l|l|l|}
\hline Parameter & Lab Reference & Result \\
\hline WBC $\left(10^{\wedge} 3\right.$ cells/ul) & $4.8-10.8$ & 14.2 \\
\hline Neutrophils.(10^3 cells/ul) $)$ & $1.9-8$ & 10.88 \\
\hline Eosinophil's & $1-3 \%$ & $2.5 \%$ \\
\hline Basophils & $0-1.5 \%$ & $0.1 \%$ \\
\hline Monocyte's $\left(10^{\wedge} 3\right.$ cells/ul) & $0.16-1$ & 1.15 \\
\hline Platelets $\left(10^{\wedge} 3 / \mathrm{ul}\right)$ & $130-400$ & 439 \\
\hline Hemoglobin $(\mathrm{g} / \mathrm{dL})$ & $12-16$ & 12.5 \\
\hline Hematocrit & $42-52 \%$ & $37.4 \%$ \\
\hline Red cell distribution width & $11.5-14.5(\%)$ & $15.4 \%$ \\
\hline Red blood cell $\left(10^{\wedge} 3\right.$ cells/ul) & $4.7-6.1$ & 4.03 \\
\hline PT-INR & $0.89-1.16$ & 1.13 \\
\hline PT-SEC $(\mathrm{sec})$ & $10-13.5$ & 13.8 \\
\hline APTT-sec $(\mathrm{sec})$ & $26-39$ & 34.1 \\
\hline
\end{tabular}

*Chemistry tests did not show any pathological findings.

Table 2: Patient's Virology Tests.

\begin{tabular}{|l|l|l|}
\hline Parameter & Lab Reference & Result \\
\hline Hepatitis A & Positive/Negative & Negative \\
\hline Hepatitis B & Positive/Negative & Negative \\
\hline Hepatitis C & Positive/Negative & Negative \\
\hline Q-FEVER phases & Positive/Negative & Negative \\
\hline Epstein-Barr virus & Positive/Negative & Positive \\
\hline BRUCELLA Ab R.Bengal & Positive/Negative & Negative \\
\hline CMV & Positive/Negative & Negative \\
\hline
\end{tabular}

Table 3: Patient's Rheumatologic Tests.

\begin{tabular}{|l|l|l|}
\hline Parameter & Lab Reference & Result \\
\hline Antinuclear antibody (ANA) & Positive/Negative & Negative \\
\hline Anti-Neutrophils Cytoplasmic Antibodies (ANCA) & Positive/Negative & Negative \\
\hline
\end{tabular}

Table 4: Patient's Stanford University Pathology Lab Findings.

\begin{tabular}{|l|l|l|l|}
\hline Label & Marker For & Results & Special Pattern or Comments \\
\hline HGAL & (Human Germinal center Associated Lymhpoma): Germinal center Bcells. & POSITIVE & NON \\
\hline CD10 & Calla, follicular lymphoma, B-ALL & NEGATIVE & POS INTERNAL CONTROL \\
\hline EMA & Epithelial membrane antigen: anaplastic lymphoma & NEGATIVE & POS INTERNAL CONTROL \\
\hline CD23 & FcRigE, CLL, FDC & EQUIVOCAL & NO+INTL CONTROL \\
\hline BCL6 & Follicular Lymphoma & POSITIVE & NON \\
\hline
\end{tabular}


Table 5: The immunohistologic differences between our reported patient comparing with the previous reported five patients

\begin{tabular}{|l|l|l|l|l|l|}
\hline Immunohistologic Findings Results & CD-20 & EMA & CD-30 & CD-15 & PD-1staining \\
\hline Our Case & Positive & Negative & Positive & Expression & $\begin{array}{l}\text { Negative with rosette formation around } \\
\text { the large atypical B cells }\end{array}$ \\
\hline Previous Five Patients & Positive & Negative & $\begin{array}{l}\text { Positive only in } \\
\text { one patient }\end{array}$ & $\begin{array}{l}\text { Expression } \\
\text { in 4 cases }\end{array}$ & $\begin{array}{l}\text { Positive with prominent ringing pattern } \\
\text { around the large atypical B cells }\end{array}$ \\
\hline
\end{tabular}
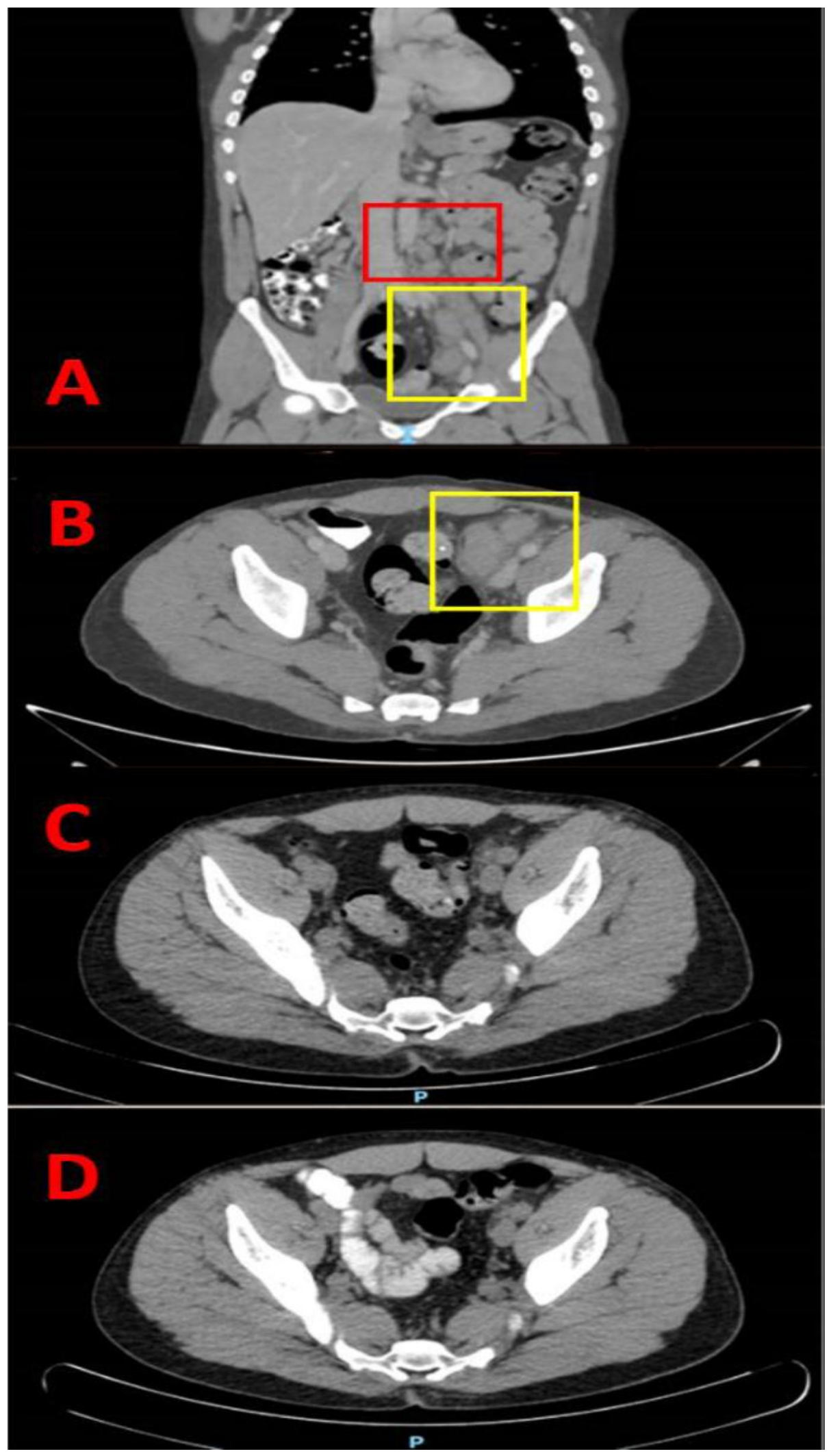

Figure 1: Shows the patient's radiological response (CT sections) to the treatment. (Red square- significant lymph node enlargement with several enlarged retroperitoneal nodes at presentation), (Yellow squares- lymphadenopathy in the left iliac area and edema at presentation). 

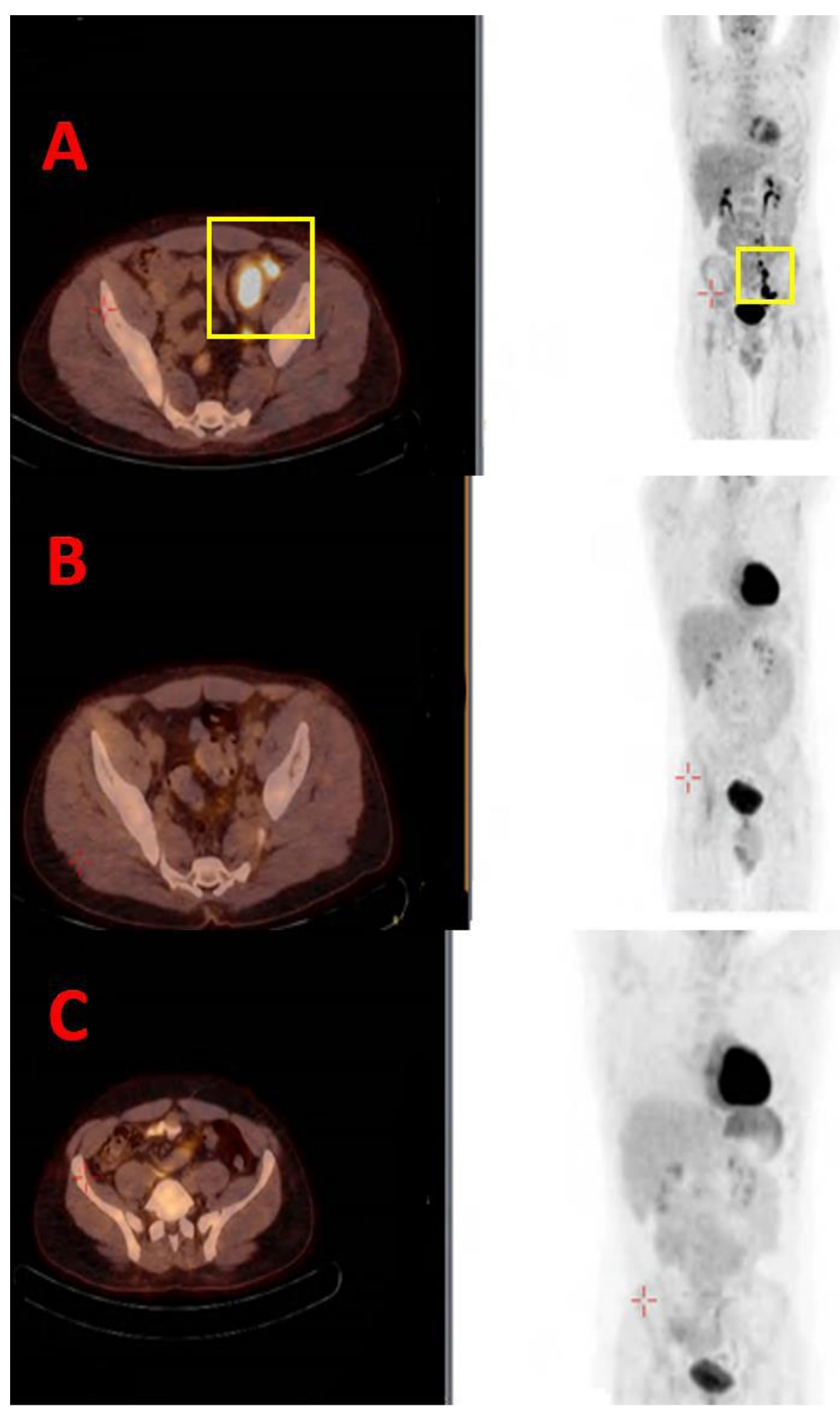

Figure 2. Shows the patient's radiological response (PET-CT selections) to the treatment. (Yellow squares- hyper-metabolic uptake and lymphadenopathy of the left iliac areas. 


\section{Discussion}

We have described a patient who had one of the rarest types of lymphoma (5 previous reported cases, the last in 2014). Our case is the youngest patient to be reported and the first to be reported from the Middle-East.

Furthermore, if we compare (immunohistologic findings) our patient with the previous five reported patients we see that the large atypical cells in all five cases expressed CD-20, the same was in our case. Epithelial membrane antigen (EMA) was negative in the previous five reported patients, the same was in our case. CD30 was positive only in one of the five cases, also in our case it was positive. Lack of CD-15 expression was seen in four of the previous reported cases, also in our case it was expressed. The previous five reported patients were all positive for PD-1staining and showed a prominent ringing pattern around the large atypical B cells, but our patients' staining for PD-1 was negative and showed rosette formation around the large atypical B cells (Table 5.). ${ }^{[5]}$.

We suggest that in a patient of any age it is important to consider the possibility of unusual malignancies when the diagnosis at first is not clear-cut, particularly today in the era of molecular medicine and tumor subtyping.

\section{Data Availability}

Not applicable

\section{Disclosure Statement}

The authors declare no conflict of interest.

\section{Funding Sources}

The authors received no financial support for the research, authorship, and/or publication of this article.

\section{Acknowledgements}

The authors thank David B. Geffen, MD for his critical review of the manuscript.

\section{Statement of Ethics}

The authors have no ethical conflicts to disclose.

\section{References}

[1] el Weshi A, Akhtar S, Mourad WA, Ajarim D, Abdelsalm M, Khafaga Y, et al. T-cell/histiocyte-rich Bcell lymphoma: Clinical presentation, management and prognostic factors: Report on 61 patients and review of literature. Leukemia and Lymphoma [Internet]. $2007 \mathrm{Sep}$ [cited 2020 Sep 8];48(9):1764-73. Available from: https://www.tandfonline.com/doi/abs/10.1080/10428190 701559124

[2] Swerdlow SH, Campo E, Pileri SA, Lee Harris N, Stein $\mathrm{H}$, Siebert R, et al. The 2016 revision of the World Health Organization classification of lymphoid neoplasms [Internet]. Vol. 127, Blood. American Society of Hematology; 2016 [cited 2020 Sep 8]. p. 2375-90. Available from: /pmc/articles/PMC4874220/?report=abstract

[3] Hartmann S, Eichenauer DA, Plütschow A, Mottok A, Bob R, Koch K, et al. The prognostic impact of variant histology in nodular lymphocyte- predominant Hodgkin lymphoma: A report from the German Hodgkin Study Group (GHSG). Blood [Internet]. 2013 Dec 19 [cited 2020 Sep 8];122(26):4246-52. Available from: https://pubmed.ncbi.nlm.nih.gov/24100447/

[4] Nam-Cha SH, Roncador G, Sanchez-Verde L, MontesMoreno S, Acevedo A, Domínguez-Franjo P, et al. PD-1, A follicular T-cell marker useful for recognizing nodular lymphocyte-predominant Hodgkin lymphoma. American Journal of Surgical Pathology [Internet]. 2008 Aug [cited 2020 Sep 8];32(8):1252-7. Available from: https://pubmed.ncbi.nlm.nih.gov/18594468/

[5] Treetipsatit J, Metcalf RA, Warnke RA, Natkunam Y. Large B-cell lymphoma with T-cell-rich background and nodules lacking follicular dendritic cell meshworks: Description of an insufficiently recognized variant. Human Pathology. 2015 Jan 1;46(1):74-83. 